\title{
DESIGNING SYSTEMS FOR E-COMMERCE
}

\author{
Shona Leitch and Matthew Warren \\ School of Information Technology, \\ Deakin University, Australia. \\ E-mail: shona@deakin.edu.au
}

\begin{abstract}
Ethics is an important element in all aspects of computing, but proves to be a real problem in the development and delivery of E-Commerce systems. There are many aspects of ethics that can affect E-Commerce systems, but often research is focused on the ethics after the E-Commerce system has been implemented, focusing on issues such as trust, privacy and disclosure.

This paper will discuss how ethical matters can affect the design of E-Commerce systems and how a framework designed for E-Commerce can be used to create and deliver effective, ethical E-Commerce systems.
\end{abstract}

Keywords: E-Commerce, Ethics and Development.

\section{INTRODUCTION}

There is a lot of talk especially in the popular press as to the virtual explosion of E-Commerce over the past few years, however many reports indicate otherwise. Or at least indicate that this 'explosion' is only taking place in certain sub-sections of the E-Commerce industry.

According the National Office for the Information Economy (NOIE, 2001) over a half of Australia's population has a personal computer in their homes and 35\% have Internet access. Along the same lines, most medium-sized businesses and over $80 \%$ of what is termed small business use personal computers. 'Over 35 per cent of all businesses have an online presence - a comparative business advantage that translates into Australia being consistently rated in the top ten nations globally for its e-commerce environment.' However this does not necessarily mean that Australia is performing and using E-Commerce well, a web presence does not necessarily mean 'electronic commerce' either. And further enlightenment from NOIE comes from the following statement:

Five per cent of Australian adults shopped via the Internet in the 12 months to February 2000, and 74 per cent paid for their purchases online. Take up rates of other kinds of e-commerce-such as telephone banking and electronic funds transfer-were even higher.' (NOIE, 2001)

The aim of the research was to produce a workable framework, which incorporates parts of previously validated systems design methodologies that encompasses all the needs and requirements of users in an ECommerce environment. By using a mixture of methodologies, we are able to also consider the fact that the system is designed ethically.

One concern that we need to consider is that the 'systems' part of an 'information system' (including ECommerce systems) represents a way of seeing the set of interacting components, such as:

- $\quad$ People (e.g. systems analysts, users)

- Objects (e.g. computer hardware devices)

- $\quad$ Procedures (e.g. those suggestions made in an IS development methodology)

(Avison, 1999)

Often in systems design, the developers focus on the objects, i.e. making the most technologically advanced system. In the case of E-Commerce B:C systems, the users are focussed upon in an attempt to sell more product and market more effectively, and often in a way that encourages unethical practices when designing systems rather than producing a system that is in the users best interests.

\section{PROJECT SUCCESS AND FAILURE}

At the present time Internet businesses have access to a wide audience with $11 \%$ of Australian households with Internet access and over $40 \%$ of U.S households. Therefore, there must be other reasons why people do not utilise online web retail or undertake B:B transactions. 
E-Commerce poses unique design issues (Leitch, 2001):

- Fast development time

- Lack of expertise in systems design means the need for an easy to use method

- High failure rate, due in part to poor systems analysis and design

- Heavy user considerations, particularly in B:C

One example of an E-Commerce failure was the UK online retailer, BOO.com. Who even though had a potentially huge client base failed to capitalise on this due to poor systems design and web design and a lack of consideration of users:

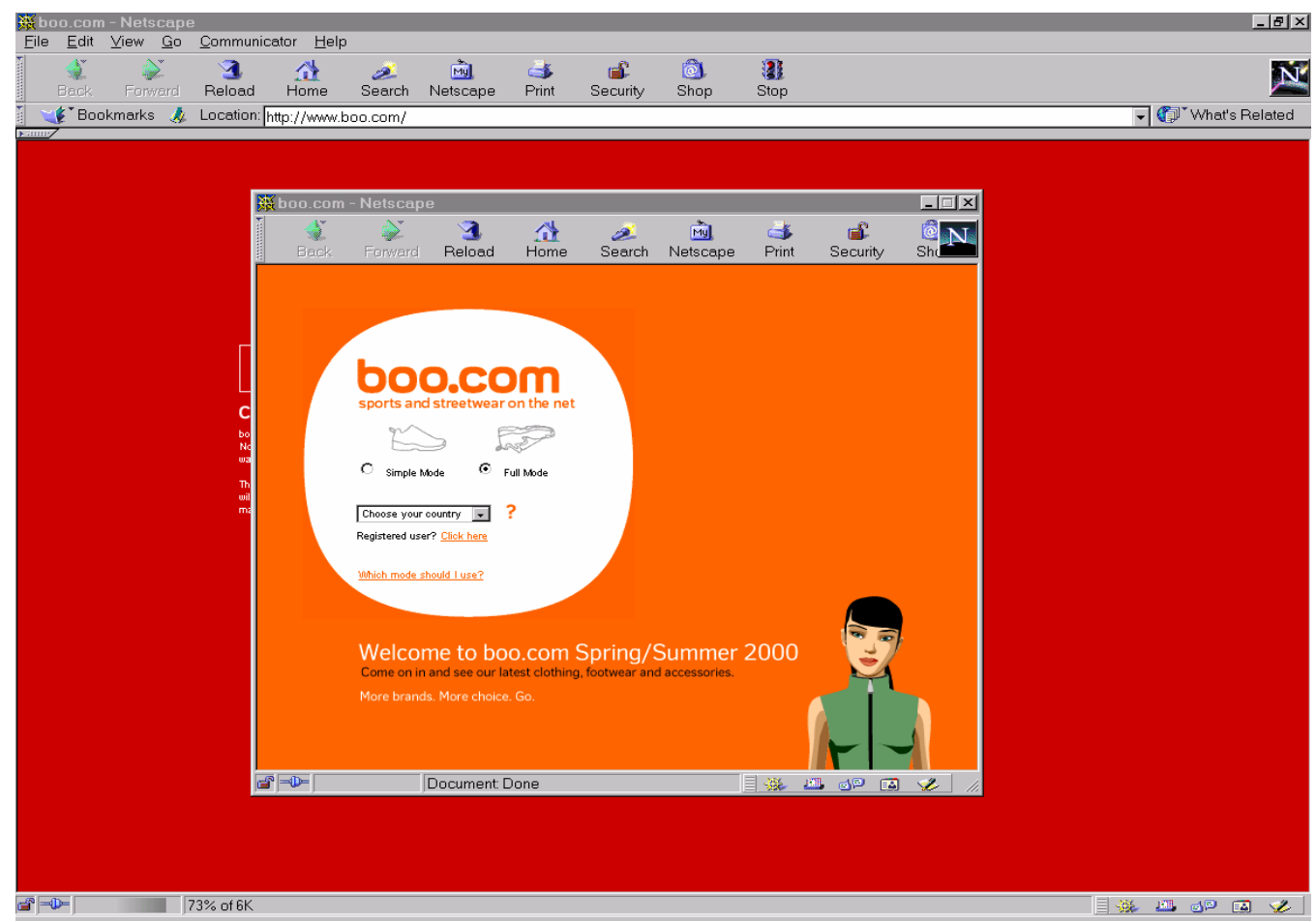

Figure 1 - Website of BOO.com

The reason for failure was that a large proportion of its potential market was unable to use Boo's site because the website design was too advanced for most computers and access frustratingly slow (BBC, 2000). Other reasons for BOO.com failure included:

- $\quad$ the site could not be seen by people who use Macintosh computers.

- $\quad$ it used lots of graphics, pop-up windows and 3-D images that only those with a 56k modem could see it without waiting minutes for it to load.

- the site was very difficult to navigate around. Shoppers could get lost and find no way back to their starting point.

- $\quad$ BOO.com was funded to the tune of some $\mathrm{A} \$ 180 \mathrm{~m}(£ 80 \mathrm{~m})$. Boo's problems also centered on its inability to build up numbers of buying customers fast enough, to generate revenues to offset steep set-up costs.

It is probable that a use of systems analysis techniques could have overcome these problems.

"Firms that cannot deliver - either because their web site is poorly designed or because their distribution system is not up to scratch - are bound to fail" $\quad$ (BBC, 2000)

The concerns of system success and failure are very real. Within any new computer system, a great deal of time, effort and monies are invested, with little guarantee of there being success at the end of the project. 
Companies that employ system designers, or model, analyse and plan their system would seem to have the best chance at achieving a truly helpful, workable system.

The rise of the Internet as a locus of business is changing marketing, for instance. It makes possible one-onone marketing by tracking the customer, recording his or her preferences and proclivities, and presenting the customer with products that he or she is likely to want to buy. High street stores, similarly to TV ads, have to generalise their marketing to an average consumer. The Internet makes it possible for a company to design a system that lets each consumer have an individual fit. This can be done to aid the user, by remembering certain likes and dislikes, but more often that not, it is done unethically to entice people to buy things they do not need through a huge purchase driven experience.

By incorporating a participational aspect to systems design, and including the user at this stage it is very likely that a system would be developed that is more ethically sound to those B:C E-Commerce customers.

But other studies have identified advantages in using a participational approach. Adams (1984) found that:

- $\quad$ Staff/users have ideas which can be useful;

- effective upwards communications are essential to effective decision making at the top;

Prior research had found that failure of E-Commerce design in an Australian context could have been resolved by a number of factors including design participation of users (Leitch and Warren, 2003).

\section{FRAMEWORK OVERVIEW}

The authors have developed a framework which could be used for the design of E-Commerce systems, focusing upon user requirements. The issues of ethical design can be resolved by ensuring that users are key stakeholders in the design of the systems that they will be using. The stages of the framework are:

Stage 1 - Strategic and Business Evaluation

1. Assess present level of E-Commerce against criteria.

Criteria:

Level 1 - No web presence

Level 2 - Have web presence (website with contact data etc)

Level 3 - Have web presence and use B:B

Level 4 - As level 3 and use B:C

Level 5 - Use both B:B and B:C

2. Decide future level, of E-Commerce using the above criteria.

3. Create detailed plan for business/systems development

- $\quad$ Set up project team

- $\quad$ Identify key business activities (BSP)

- Develop a formal plan (objectives, goals, resources) (Lederer and Mendelow, 1989)

- Link E-Commerce plan to business plan

- Perform cost benefit analysis - identifying tangible and intangible benefits

- Prepare for change

4. Perform feasibility and SWOT analysis

- $\quad$ Define information systems outline

- $\quad$ Select feasibility options

- Identify strengths, weakness, opportunities and threats

- $\quad$ Create feasibility report

Stage 2 - Systems Analysis and Design

1. Create rich pictures from level 2 and 3 of stage 1 to create a conceptual model of system and user requirements.

2. Apply a participational Approach to level 1

- Use a cross census of users to discuss the rich pictures

- Reflect on outcomes of discussions

- If possible, assess E-Commerce user requirement, also using the participational approach (perhaps with a pilot group of Internet users)

- $\quad$ Reflect again on these outcomes

3. Create final rich picture

1. Undertake process modelling

Stage 3 - Systems E-Commerce Design

2. Assess technical considerations

3. Assess security considerations 
Stage $4-$ Im
1. The physical implementation of the web-site.

Stage 5 - Post Implementation

1. Using the participational approach, discuss and reflect on issues arising through implementation.

Stage 1 of the framework could be compared to traditional systems analysis and design methods that implement feasibility studies, requirements elicitation or other problem identifying skills. Although part of the beginning of this framework aims to also provide some insight into the feasibility of an E-Commerce project, it also provides a much deeper, strategic and business evaluation than using just one of the above. From current statistics of organisations use of feasibility studies, two thirds of organisations did not conduct / sometimes conducted a feasibility study (Leitch, 2001). It is also believed that the inclusion of a feasibility aspect of the design, will encourage companies to assess their business function and customers wants, needs and expectations. The benefits of feasibility studies are widely reported, and therefore it was decided to include an ad-hoc one within this framework.

Initially it was decided that a developer would first have to decide at what 'stage' of E-Commerce the organisation was at. This is deemed to be important, as many e-commerce businesses as they define themselves are little more than an online advertisement. Therefore by categorising themselves, it is easier to proceed through other levels of E-Commerce development. As at this initial level, it is suggested that the developer/analyst also decides to which level the organisation wishes to pertain through the development of the present project.

A large amount of focus on the new framework for E-Commerce was put into the strategic and planning stages, although this is not aimed at taking up a large amount of a potential analyst's time, it is perceived to be straightforward enough to do in a timely manner whilst still providing a developer with enough information and safeguards to know that their project has merit. Therefore, in the $3^{\text {rd }}$ step of stage 1 , it is suggested that the developers do a number of formal steps to aid in the proposed project.

In Stage 2 of the framework, a number of traditional steps were used, in order to provide the best possible analysis stage for the area of E-Commerce. The needs of e-commerce in terms of systems analysis and design are not adequately covered in any of the major methodologies and frameworks that have been written so far. However parts of these methodologies and frameworks have aspects that are relevant and useful to ECommerce design.

The use of a form of rich pictures (Checkland, 1981) will both incorporate the users of a system, as well as providing an easy to understand and relate to method of eliciting and discussing information between the designers and other stakeholders. It is suggested that ETHICS (Mumford, 1983) is used as the way to conduct these meetings. This information can then be taken by the designers and created into simple DFD style diagrams for the coding stage. Again post-implementation will make use of a particpational approach to assess the new system.

Stage 3 of the framework is focused upon a more traditional system design viewpoint in terms of process definition, use of appropriate technologies and how to implement required security features. Stage 4 is the actual implementation of the system.

Stage 5 focuses upon the post implementation aspect. The design groups reflects upon the design of the system and uses a participational approach to overcome any problems that may have arisen.

It is not being suggested that designers follow methodologies closely, this framework is suggesting the best methods to use to create a new E-Commerce system, and recommends the principles of some tried and tested methodologies are implemented, but as the need for a fast creation time is paramount, then the full and detailed layout of each type of methodology will not be followed.

This framework will be validated by helping to designing a number of E-Commerce systems.

\section{CONCLUSION}

The results of this unique research, with the analysis of the most commonly utilised systems analysis methodologies as well as considering the wants and needs of organisations creating E-Commerce solutions, will allow for the production of a framework capable of assisting in more effective, successful and ethical ECommerce systems. 


\section{REFERENCES}

Adams, W. (1984) “Participation Today”, The Industrial Participation Association, UK.

Avison, P. \& Fitzgerald, G., (1999) "Information Systems Development: Methodologies, Techniques and Tools". McGraw-Hill, UK.

BBC (2000) 'From Boo.com to Boo.gone' http://news.bbc.co.uk/1/hi/business/753782.stm [accessed 14/08/02]. Checkland, P. (1981) "Systems Thinking, Systems Practice”. Wiley, Chichester.

Lederer, A. L. \& Mendlelow, A. L. (1989) "Information systems planning: incentives for effective action" Data Base, Fall.

Leitch, S. (2001) "The use of Electronic Commerce and Systems Design within Australian Organisations", Deakin University Technical Paper, Australia.

Leitch, S. and Warren, M.J. (2003) A Quality Indicator of Australian E-Business, The E-Business Review, Vol III, International Academy of E-Business, USA.

Mumford, E. (1983) “Designing Participatively”, Manchester Business School, UK, ISBN 0-903808-29-3.

NOIE (2001) "E-Commerce across Australia" NOIE (National Office for the Information Economy), Canberra, Australia. 